Please quote as: Kneißl, F.; Röttger, R.; Sandner, U.; Leimeister, J. M. \& Krcmar, H. (2009): All-I-Touch as Combination of NFC and Lifestyle. In: Proceedings of the 2009 First International Workshop on Near Field Communication, IEEE Computer Society, Washington, DC, USA. 


\section{All-I-Touch as Combination of NFC and Lifestyle}

\author{
Fabian Kneißl and Richard Röttger \\ Center for Digital Technology \\ and Management \\ 80290 Munich, Germany \\ \{fabian.kneissl,richard.roettger\}@cdtm.de
}

\author{
Uwe Sandner, Jan Marco Leimeister \\ and Helmut Krcmar \\ Technische Universität München \\ 85748 Garching, Germany \\ \{sandner,leimeister,krcmar\}@in.tum.de
}

\begin{abstract}
For this paper we developed the concept and implemented a fully working prototype of a snowboarder community platform based on Near Field Communication. All-I-Touch is a service which provides product information at the point of sale and additionally connects the user with his social community in Facebook. Through this combination it is possible to increase incentives for the end user to use the service as well as the snowboard manufacturer to equip his products with NFC tags. The end user benefits from meaningful product information which is enriched with comments from his friends or arbitrary users through the connection to Facebook. This information is more likely to represent an independent impression of the product than the manufacturer's description and thus it is more valuable. On the other hand, manufacturers profit from All-I-Touch as a tool for Viral Marketing and benefit from a highly relevant target group. To enhance the attractiveness of the Facebook application we extended All-I-Touch to include Pieces, Places and People. Thus, the user can update his Facebook profile page instantly with information like where he has been and whom he met - and all that just by holding a mobile phone over a tag!

Index Terms-Near Field Communication, Social communities, Viral Marketing, Innovation, Lifestyle
\end{abstract}

\section{NFC FOR SOCIAL INTERACTION}

In the recent past, several mobile phones got equipped with Near Field Communication capabilities. Although this technology allows a multitude of easy to use applications like payment, ticketing or access control, the Gartner institute predicts a market penetration of NFC capable end devices of only about $20 \%$ globally until 2012 [9]. In our opinion, one reason for this lies in the focus on payment and ticketing where even researchers see issues about security [5]. Furthermore, a study of the European Central Bank shows that merchants have limited interest in offering new payment services [7]. These reasons emphasize the need for a widely accepted, customer focused application outside the domain of payment and ticketing. With such a service, the deadlock that service providers wait for mobile phone manufacturers to equip their devices with NFC technology in order to launch their services and vice versa may be solved. Section II examines why our service helps to reach a mass market even though we focus on the smaller snowboarder market in the beginning.

There is also a strong trend to bring desktop Internet applications to the mobile market, pushed by the new generation of cell phones like the iPhone. To monetize this trend for NFC we looked at the most popular Internet services available today. Statistics show that social networks clearly have a huge market

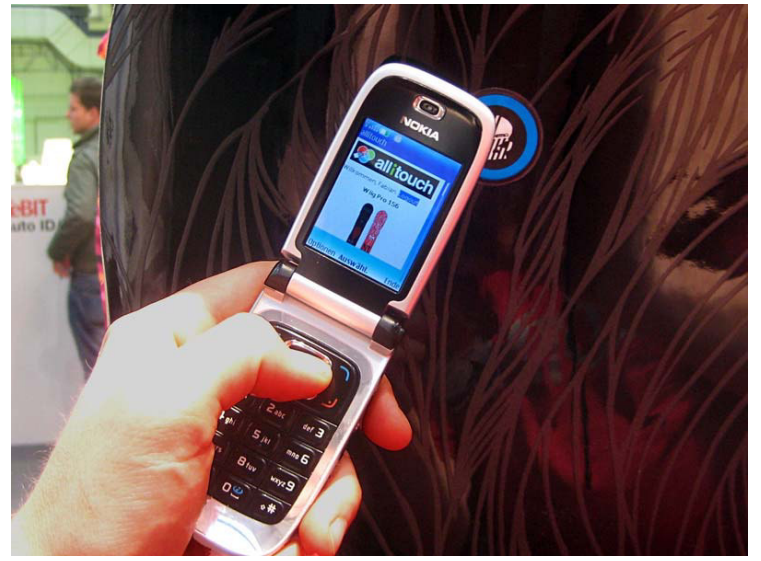

Figure 1. Detailed product information is displayed immediately after touching the NFC tag on the snowboard.

share of services in the Internet: Facebook and MySpace are among the ten most used web pages worldwide according to [2]. Another fact to take into account is the enormous success of Twitter, a platform where users can state what they are doing right now using short status messages. Twitter is among the Alexa top 500 in the USA, considering that the application can be used without visiting the web page. This is a good example for the willingness of people to present themselves in the Internet and let everybody be part of their life. Furthermore, shopping sites are of big importance, for example eBay and Amazon are among the top 10 in Germany [3].

So far, solutions which deliver product information at the point of sale neglect the huge social component of shopping. At this point, All-I-Touch differentiates from other comparable services as the thrill of social networks is added to the provided information by means of friends' recommendations and the instant profile update in Facebook. In order to increase the social component of All-I-Touch, it is also possible to touch other people and places. Again, this automatically updates the Facebook application and everybody can show his community where he has been and whom he has met - and all that just by touching an NFC tag, satisfying the self representation need.

\section{SERVice Functionality}

All-I-Touch provides a mobile phone interface together with a cross-vendor online platform as well as a Facebook 
application. Users can touch ${ }^{1}$ pieces, places and people with their NFC capable mobile phones in order to inform friends what they touched, get information, receive comments from their friends and share their own opinion. This information is also available online on the All-I-Touch website. Furthermore, a Facebook application was developed that shows the latest events from the user himself and the latest events from his friends. Thus, the user is always informed what his fellows have recently touched and thereby what they have done.

\section{A. Snowboarders as Ideal Target Group}

An essential prerequisite for starting this service is the focus on a clearly defined, narrow market. At the first glance, this sounds counterproductive to the goal of reaching a wide user base. But for a not yet existing service this is the only way to cover a remarkable share of the market segment right from the beginning. When the service is successful in this particular market segment, the experience and the brand name can be used as steppingstone into new and broader markets. Besides having a clearly defined market, the offered products have to fulfill special requirements, too. According to [15], the need for information at the point of sale increases for "products that use a higher degree of collective decision making and have less routine purchasing". This means that the best fitting products for All-I-Touch should be of a higher price and purchased in a small amount. Furthermore, the customers in this market segment should have an affinity to lifestyle as well as to new ways of communication and technology. We discovered that snowboarders ideally fit to this group as a) this sport activity is a way to express ones lifestyle through its practice and apparel, and b) younger people use new technology and social networks extensively [10]. Also, snowboards themselves are highly specialized and expensive products and thus match the above-mentioned requirements for the market.

\section{B. Use Cases: Product Information, Localization, Communi- cation}

The following use cases will clarify what the service in particular is about. Let us assume that a snowboard test event takes place in a ski resort. They are usually held by manufacturers many times during the season to present their latest equipment which is available for test riding.

Pieces. All-I-Touch user Alice wants to get a new snowboard and thus touches NFC tags on snowboards she likes with her NFC capable mobile phone. She gets detailed information on this particular board and also comments from her friends on Facebook are displayed. Instantly, her Facebook profile is updated and her event of touching this board is not only shown on her own profile page, but also on her friends' profiles. After testing the board, she leaves a comment on the product site of the board expressing her satisfaction. This comment can also be seen by other users.

Places. At the end of the snowboard day, Alice attends a snowboarder after-party. She wants to show her friends what

\footnotetext{
${ }^{1}$ Touch: action of reading an All-I-Touch NFC tag with a mobile phone and transferring the web page from the server
}

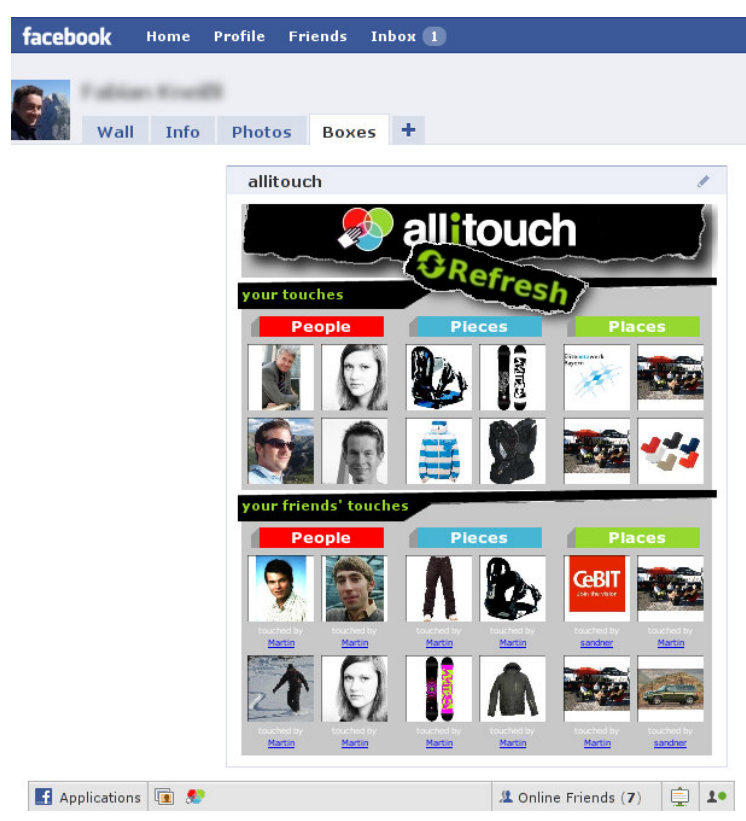

Figure 2. The screenshot of the All-I-Touch Facebook application shows the recent activities of the user and his friends.

a cool party this is, touches an NFC tag on this event and saves it together with a comment on her profile. Also here, her friends see on the All-I-Touch website and Facebook that Alice attended this event.

People. At the party, she gets to know another snowboarder called Bob. They want to stay in contact and thus touch each others name badges. These NFC enabled badges are provided by the party host and contain their contact information. Like that, their encounter is saved to their online profiles and to Facebook.

Having had a great day, she relaxes at home and reviews her entire day on the All-I-Touch website: It reminds her of the boards she tried and commented on, thus she can decide on what board to buy. Also, her new friendship with Bob is displayed and they can stay in contact via Facebook.

\section{Challenges: Business Case and Interaction Design}

Along with the use cases described above, the following problems get addressed:

- Users want detailed information about a product before they buy it, especially if the product is expensive like snowboards are [15]. All-I-Touch facilitates the user's buying decision by providing this information at the point of sale. Hereby, the information can not only be gained through Internet research, but also mobile. Especially for impulsive purchases, this service supplies meaningful help for the decision.

- A further incentive to use the service is that one is no longer dependent on potentially biased information from the salesperson. Instead, comments from non-party users may draw a more realistic picture of the product, especially if the information is provided by one of the user's 
friends. Moreover, not only technical details influence the buying decision, but they also must fit into the user's way of life and be acknowledged by friends in order to create the desired exterior impression. Thus, opinions of friends are an important means of assurance for the user. Besides, he also wants to share his experience with his friends and therefore can leave comments.

- In online social networks, many users like to include self-portrayal elements on their profile page and keep an online diary to a certain extent. Updating the profile requires a lot of time and effort which one may not have for example on a journey. All-I-Touch lessens this inconvenience with its Facebook application which allows the user to update his profile with the latest persons he met and places he has been to, just by a simple and easy touch. For example touching the tag of a black piste in a ski resort supporting All-I-Touch will result in an automatic Facebook status update like "Alice mastered the black piste at the ski resort XY!" without any further interaction from Alice.

Not only the customer benefits from the usage of All-I-Touch but also there are several advantages for manufacturers as well:

- According to [13], 79\% of all Facebook users are between the age of 12 to 35 and thus in a very important target group. Equipping products with All-I-Touch NFC tags attracts especially these technical affine, young users as they benefit from the social network function coming along with our service. In other words, with All-I-Touch the manufacturers can directly address exactly these users and gain an advantage against manufacturers not using it.

- All-I-Touch can be used as a tool for Viral Marketing. This type of marketing utilizes the user in a way that he sends some form of content provided by the company to his friends if the content is worth being sent [11]. As products which were touched by a user get visible to all his friends by means of the Facebook application, certain awareness is generated for a product and thus can be seen as Viral Marketing. This is not only true for manufacturers, but also for operators of locations like the ski resort mentioned above. Consider that an opinion leader touches products from a specific brand very often. This will lead to a positive perception of that brand within his circle of friends. Such networking effects can boost the awareness for a that brand.

- Naturally, much customer related information can be gathered within this kind of service. But the data from All-I-Touch differentiates from usual sales data the manufacturers receive e.g. from their own online shops in one crucial point: the social context. The customer is no longer a single entity in a database but now connections between the behavior of the user and his friends can be seen. Possibly, lead users can be identified and selectively addressed which would represent a huge advantage in competition towards companies not supporting All-I-Touch.

\section{TECHNICAL IMPLEMENTATION}

\section{A. Technology setup}

As the project focuses on the idea and concept of the service successfully combining NFC and social network systems and not on the introduction of new technical approaches, the used technical setup is straightforward and just mentioned for completeness. The whole project was developed within a course called "CenterVenture". The aim of the course is to develop a fully functional prototype within five days. With respect to this tight schedule, we paid a lot of attention to flexibility in order to react quickly to new findings and constantly arising ideas. That is why we decided to follow the agile software development paradigm. From a technological perspective, we used a JBoss Application Server as Enterprise Java Bean container connected to a MySQL database. The back- to front-end propagation was done by means of Apache Struts 2. All these technologies support an agile development and at the same time provide a good scalability and robustness which would allow for use in a production environment. Our NFC system consists of NFC tags and the Nokia 6131 NFC as a mobile phone.

As we developed a typical service initiation application, we followed the specification released by the NFC Forum [8]. That means we only save a URL on the NFC tags that redirects to our web service. This is a well-established standard and thus every mobile device with NFC capabilities is able to handle these tags without the supplemental installation of special software. This is a crucial point because this is the only way we can ensure that All-I-Touch works on every NFC enabled mobile phone. On the other hand this implies that an Internet connection is required to receive the information. In the view of decreasing costs for mobile Internet with increasing transfer rates at the same time, we do not consider this to be a problem.

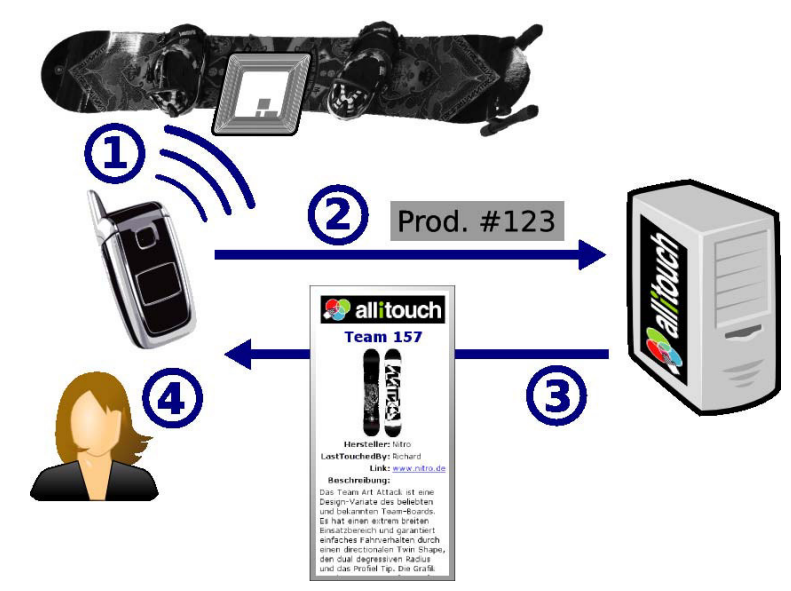

Figure 3. Through four steps the user is provided with detailed information: 1) Touch of NFC tag, 2) Request of information, 3) Mobile web page sent to mobile phone, and 4) Information displayed to user 


\section{B. Touch process}

1) A user moves his mobile phone over an object with an NFC tag. As already mentioned this can be a Piece, a Place or a Person.

2) The mobile phone reads the information stored on the tag, recognizes the URL and automatically starts the phone's own web browser. An Internet connection is established by the phone to fetch this web page.

3) The All-I-Touch server collects all information and returns a web page optimized for mobile usage. At this point the server registers the user action and updates his profile page. In order to do so, the user has to be logged in. The login information is saved in a cookie and therefore the login is a one time action. Since we designed All-I-Touch for the only NFC device available to us, we optimized the design for the screen size of this phone. For a full product that goes beyond a prototype, images and design should be adapted to device characteristics. For example the device could be identified and the user interface delivered in different sizes by means of WURFL [12], or commercially available services could be used to translate the design for different phones like it is done with Netbiscuits [1] or sevenval [17].

4) The user receives all relevant information.

Keep in mind that during all these steps only one user action is needed: the touch process. As one of the key elements, the connection of our service with Facebook will be discussed. The user has two possibilities to join All-I-Touch:

1) By registering on the All-I-Touch website.

This can be done mobile or at any desktop computer. Upon joining, the user may use the provided community functions on the website. He can form friendships, is informed about the activities of his friends and so forth.

2) By installing the Facebook application.

As the user's willingness to join and maintain an entirely new social network is low, we decided to allow the user to utilize the existing social network from Facebook. If a new user installs our application in Facebook, he can connect his Facebook account with a new or already existing All-I-Touch account.

Although All-I-Touch can be used as a stand-alone service, the full functionality is only achieved when the user profile is connected with a Facebook profile. After this connection is established, all of the user's Facebook friends who are active on All-I-Touch are automatically treated as All-I-Touch friends. So the user does not have to keep track of his friends in two different social networks, but he only keeps using his favorite existing network.

\section{CONCLUSION}

Implications: With All-I-Touch we introduced the successful combination of an NFC service-initiation application with the social network system Facebook. In our opinion, this combination is the main factor for a successful launch of the service because users as well as manufacturers benefit: Users receive more valuable and social enriched information and update their Facebook profile just by one touch. Manufacturers on the other hand profit from the access to very exhaustive customer data including relationship information between their customers. Furthermore, All-I-Touch was presented on a booth called "NFC \& Lifestyle" at the world's largest computer exposition CeBIT. During the fair experts as well as potential users verified our assumption that the features presented in All-I-Touch cumulate in a unique and outstanding new service which has the possibility to get accepted on the market.

Future development: The described idea shows that NFC technology can not only be utilized for payment and ticketing, but also adds value to lifestyle products and events. Thinking more into the lifestyle direction, NFC tags could be used at any event like concerts or football games. The direct interaction between users who do e.g. speed dating or scavenger hunt can be enhanced through tagging people or objects. After reaching a higher acceptance of NFC technology, addressing broader markets with a similar service like an interactive travel guide will be possible.

To further improve All-I-Touch, a database containing products from many manufacturers is necessary as well as the inclusion of the NFC tag into the real products. A snowboard equipment manufacturer, who supported us during the CeBIT booth, has already shown interest in placing NFC tags into their boards to allow more interaction using a mobile service.

\section{ACKNOWLEDGEMENT}

The authors would like to thank all participants of the CDTM CenterVenture who helped in creating All-I-Touch. In addition, special thanks to everyone who supported us in making the CeBIT booth a success.

\section{REFERENCES}

[1] dynetic solutions GmbH, "Netbiscuits Whitepaper: Enabling the Mobile Experience," 2007.

[2] Alexa, "Top 500 Sites," September 2008.

[3] Alexa, "German Top 100 Sites," September 2008.

[4] M. Andrews, "Decoding MySpace," US News \& World Report, vol. 18, 2006.

[5] Y. B. Choi, R. L. Crowgey, J. M. Price, and J. S. Vanpelt, "The state-of-the-art of mobile payment architecture and emerging issues," International Journal of Electronic Finance, vol. 1, no. 1, pp. 94-103, 2006.

[6] N. Davies and H.-W. Gellersen, "Beyond Prototypes: Challenges in Deploying Ubiquitous Systems," IEEE Pervasive Computing, vol. 1, pp. 26-35, January 2002.

[7] European Central Bank, "E-Payments without Frontiers," ECB Conference on 10 November 2004, 2005.

[8] Innovision Research \& Technology plc, "Near Field Communication in the real world - part II: Using the right NFC tag type for the right NFC application."

[9] N. Jones, "Important Mobile and Wireless Market Directions, 2008 to 2012," Gartner Research, 2008.

[10] Label Networks, "Largest Snowboard Consumer Research Study Provides Most Current Insight, Market Opportunities, State of the Industry, and Future Forecasting," April 2005.

[11] S. Langner, Viral Marketing: Wie Sie Mundpropaganda gezielt auslösen und Gewinn bringend nutzen. Gabler, September 2007.

[12] L. Passani and A. Trasatti, "WURFL Position Paper," in W3C International Workshop on the Implementation of a Device Description Repository, July 2006.

[13] Quantcast, "facebook.com Demographics," 2008. 
[14] J. Rayport, “The Virus of Marketing," Fast Company, no. 06, pp. 68+, 1996.

[15] F. Resatsch, U. Sandner, J. M. Leimeister, and H. Krcmar, "Do Point of Sale RFID-Based Information Services Make a Difference? Analyzing Consumer Perceptions for Designing Smart Product Information Services in Retail Business," Electronic Markets, vol. 18, pp. 216-231, August 2008.
[16] N. Rohde, "Mobile Zahlungssysteme," 2005.

[17] Sevenval, 2008. Available: http://www.sevenval.com. 